\title{
Is it possible to improve long-term results of laparoscopic adjustable gastric banding with appropriate patient selection?
}

\author{
Michał Orłowski ${ }^{1}$, Michał Janik², Paula Franczak ${ }^{1}$, Agata Frask $^{1}$, Maciej Michalik ${ }^{3}$ \\ ${ }^{1}$ Department of General and Oncological Surgery, Ceynowa Hospital, Wejherowo, Poland \\ ${ }^{2}$ Department of General, Oncologic, Metabolic and Thoracic Surgery, Military Institute of Medicine, Warsaw, Poland \\ ${ }^{3}$ Department of General, Minimally Invasive and Elderly Surgery, University of Warmia and Mazury, Olsztyn, Poland
}

Videosurgery Miniinv 2020; 15 (1): 166-170

DOI: https://doi.org/10.5114/wiitm.2019.86773

\begin{abstract}
Introduction: The gastric band is still offered as a good bariatric option for highly motivated and carefully selected patients. The question is whether this faith is justified or not.

Aim: To assess long-term clinical outcomes of patients who underwent laparoscopic adjustable gastric banding (LAGB) at a single bariatric center and to examine variables associated with patients' adherence to scheduled postoperative appointments.

Material and methods: A retrospective review of patients who underwent LAGB between 2004 and 2009 was performed. The initial cohort included 167 patients. Data regarding sex, age, preoperative weight, hometown population and distance from the bariatric center, and gastric band volume were collected. Compliance was measured as the number of postoperative appointments. Clinical outcome was defined as percent excess weight loss (\%EWL) at the end of the observation period or at band removal.

Results: The LAGB was performed in 167 patients between 2004 and 2009. The mean follow-up time was $90 \pm 24$ months. Five (3\%) patients were lost to follow-up; 37 (22.2\%) had their band removed. The remaining 125 (74.8\%) patients retained their bands and were included in the analysis. The mean \%EWL was $33.0 \pm 26.6 \%$. Thirty-one (18.6\%) patients achieved \%EWL > 50\%.

Conclusions: This study found that LAGB was not an effective bariatric procedure in long-term observation. Only $25 \%$ of 125 patients who maintained a functioning band achieved \%EWL >50\%. Compliance was the only independent prognostic factor for weight loss. Other factors had no influence on outcome.
\end{abstract}

Key words: bariatric surgery, laparoscopy, long-term follow-up, laparoscopic adjustable gastric banding, gastric band.

\section{Introduction}

Laparoscopic adjustable gastric banding (LAGB) was once considered a simple and effective bariatric procedure. In 2007 LAGB accounted for $40 \%$ of all bariatric procedures performed worldwide [1]. Promising early results and the possibility of complete reversal were responsible for great patient interest in this procedure. Unfortunately, long-term observations revealed poor effectiveness and a high complication rate [2]. In the last decade, the popularity of LAGB has dramatically decreased. At the time of the 2013 IFSO report, approximately 43,000 LAGB procedures were performed annually [1]. The LAGB still constituted $7.3 \%$ of the bariatric operations in Poland in 2016 [3]. Some surgeons still offer LAGB because the procedure can be effective and safe for highly motivated patients who meet strict criteria 
regarding compliance [4]. Knowing which factors influence compliance in bariatric patients is essential for those who still perform LAGB.

\section{Aim}

The aim of the study was to assess the long-term clinical outcomes of patients who underwent LAGB at a single bariatric center and to examine the variables associated with patients' adherence to scheduled appointments after bariatric surgery.

\section{Material and methods}

We performed a retrospective review of patients who underwent LAGB between 2004 and 2009. The 5-year results of this cohort study were published in 2011 [5]. The indications for surgery were body mass index $(\mathrm{BMI})>40 \mathrm{~kg} / \mathrm{m}^{2}$ or $\mathrm{BMI}>35 \mathrm{~kg} /$ $\mathrm{m}^{2}$ with comorbidities. Five surgeons performed the procedures with the Swedish adjustable gastric band (BD2XV with Velocity Injection Port and Applier; Ethicon Endo-Surgery), applying the "pars flaccida" technique. The band was not secured by fixation to the stomach wall and drainage was not commonly used. Oral fluids and mobilization were initiated on the day of surgery. At discharge, the patients received diet recommendations. The postoperative follow-up schedule consisted of a clinic appointment in the sixth postoperative week, then every 3 months through the first year and every 6 months thereafter. An additional phone interview was conducted by an independent investigator in May 2015. The investigator called all patients with maintained LAGB who had not attended a postoperative appointment after 1 January 2015. The initial cohort included 167 patients, 5 of whom were lost to follow-up. Data regarding sex, age, preoperative weight, hometown population and distance from bariatric center, and volume of gastric band were collected. The clinical outcome was defined as weight loss expressed as percent excess weight loss (\%EWL) at the end of the observation period or at the time of band removal. \%EWL was calculated with the following formula: (initial weight - postop. weight)/(initial weight - ideal weight), in which ideal weight was defined as a BMI of $25 \mathrm{~kg} / \mathrm{m}^{2}$ [6]. Failure was defined as $\% E W L \leq 25 \%$ or the need for band removal. A moderate effect was defined as $\%$ EWL between $25 \%$ and $50 \%$. A successful outcome was defined as \%EWL over $50 \%[7,8]$. Com- pliance was measured according to the number of postoperative appointments.

\section{Statistical analysis}

Statistical analysis was performed with Statistica software, version 12 (StatSoft). Normality of the data was tested with the Shapiro-Wilk test. Continuous variables were compared with the Wilcoxon signed-rank test or the Kruskal-Wallis test. Correlations were assessed with Spearman's correlation test. Categorical variables were compared with the $\chi^{2}$ test. Statistical significance was set at $p<0.05$.

\section{Results}

Between 2004 and 2009, 167 patients underwent LAGB at our institution. One hundred sixty-two (123 women, 39 men) of them attended a minimum of one follow-up visit. Five patients were lost to follow-up. There was no perioperative mortality. One patient died 6 years after LAGB of complications from cardiac surgery. Table I presents baseline characteristics of the cohort. Bands were removed in $22.8 \%$ of patients $(n=37)$. Twenty-one patients underwent removal because of complications: slippage $(n=8)$; band infection $(n=8)$; intolerance $(n=3)$; band erosion $(n=2)$; other $(n=1)$ and 12 because they were unsatisfied with their weight loss. The remaining $77.2 \%$ of patients $(n=125)$ retained a functioning gastric band and were included in the analysis. The mean length of observation was 90 \pm 24 months. The mean \%EWL was $33.0 \pm 26.6 \%$ and the mean percent total weight loss (\%TWL) was 15.4 $\pm 12.5 \%$ (Table II). Thirty-one (25\%) of 125 patients achieved successful outcomes; 49 (39\%) achieved moderate weight loss. Unsuccessful outcomes were observed in 45 (36\%) patients.

Sex, age, preoperative $\mathrm{BMI}$, and band volume were not significantly associated with weight loss

Table I. Demographic data $(n=162)$

\begin{tabular}{|c|c|c|}
\hline Basic characteristics & Value & $\%$ or (SD) [range] \\
\hline Mean age [years] & 39.1 & $( \pm 10.8)[19.0-74.0]$ \\
\hline Sex (female/male) & $123 / 39$ & $75.9 \% / 24.1 \%$ \\
\hline $\begin{array}{l}\text { Mean preoperative } \\
\text { weight }[\mathrm{kg}]\end{array}$ & 137.1 & $( \pm 28.4)[90.0-240.0]$ \\
\hline $\begin{array}{l}\text { Mean preoperative } \\
\text { BMI }\left[\mathrm{kg} / \mathrm{m}^{2}\right]\end{array}$ & 48.0 & $( \pm 8.5)[46.7-49.4]$ \\
\hline
\end{tabular}


Table II. Long-term outcomes of LAGB among patients who maintained the gastric band $(n=125)$

\begin{tabular}{|c|c|c|}
\hline Variable & Value & $\%$ or (SD) [range] \\
\hline $\begin{array}{l}\text { Follow-up period } \\
\text { [months] }\end{array}$ & 90 & $( \pm 24)[64-120]$ \\
\hline$\% E W L$ & $33.0 \%$ & $( \pm 26.6)[-58-108 \%]$ \\
\hline$\% T W L$ & $15.4 \%$ & $( \pm 12.5)[-20-50.3 \%]$ \\
\hline$\Delta \mathrm{BMI}\left[\mathrm{kg} / \mathrm{m}^{2}\right]$ & 7.6 & $( \pm 6.5)[-8.2-26.3]$ \\
\hline $\begin{array}{l}\text { Number of patients } \\
\text { with } \% E W L>50 \%\end{array}$ & 31 & $25 \%$ \\
\hline $\begin{array}{l}\text { Number of patients } \\
\text { with } \% \text { EWL }>25 \% \\
\text { and } \leq 50 \%\end{array}$ & 49 & $39 \%$ \\
\hline $\begin{array}{l}\text { Number of patients } \\
\text { with } \% E W L \leq 25 \%\end{array}$ & 45 & $36 \%$ \\
\hline
\end{tabular}

outcome. As expected, patients with successful outcomes were more compliant than other patients (Table III). We found that age was correlated with the number of postoperative appointments; older pa- tients statistically significantly more often appeared at follow-up examinations ( $R=0.19, p=0.016)$. Hometown population and distance to the bariatric center were not associated with the number of postoperative appointments (Table IV).

Among all 162 patients, 31 (19\%) achieved a successful outcome. Failure was observed in $51 \%$ of patients $(n=82)$. Forty-five of 82 patients with weight loss failure achieved an EWL < 25\%; 37 underwent band removal. In $30 \%$ of patients ( $n=49$ ), moderate weight loss was achieved. Percentage of patients who attended postoperative appointments presented in Figure 1.

\section{Discussion}

The LAGB evolved from vertical banded gastroplasty. Early results were promising [9]. The procedure raised great interest among surgeons and patients because of safety considerations, effectiveness, and accessibility. However, long-term observations of patients who underwent LAGB revealed serious prob-

Table III. Differences among patients according to weight-loss outcome

\begin{tabular}{|c|c|c|c|c|}
\hline \multirow[t]{2}{*}{ Variable } & \multicolumn{3}{|c|}{ Weight-loss outcome } & \multirow[t]{2}{*}{$P$-value } \\
\hline & $\begin{array}{c}\text { Success } \\
\% \text { EWL > } 50 \%\end{array}$ & $\begin{array}{c}\text { Moderate } \\
\% \mathrm{EWL}>25 \% \\
\text { and } \leq 50 \%\end{array}$ & $\begin{array}{c}\text { Failure } \\
\% \text { EWL } \leq 25 \%\end{array}$ & \\
\hline Mean age [years] & $39.1 \pm 12.4$ & $38.6 \pm 9.6$ & $37.6 \pm 11.4$ & 0.662 \\
\hline Mean preoperative BMI $\left[\mathrm{kg} / \mathrm{m}^{2}\right]$ & $46.8 \pm 6.7$ & $48.1 \pm 9.6$ & $48.4 \pm 8.8$ & 0.904 \\
\hline Number of postoperative appointments & $6.8 \pm 3.8$ & $4.6 \pm 3.1$ & $4.6 \pm 3.6$ & 0.008 \\
\hline Follow-up period [months] & $60.0 \pm 37.0$ & $44.9 \pm 37.6$ & $58.0 \pm 40.1$ & 0.128 \\
\hline Volume of gastric band [ml] & $5.7 \pm 3.1$ & $6.0 \pm 3.3$ & $5.8 \pm 3.6$ & 0.960 \\
\hline
\end{tabular}

$B M I-$ body mass index.

Table IV. Number of postoperative appointments according to sex, city size, and distance from home to bariatric center

\begin{tabular}{|c|c|c|c|c|c|c|c|c|c|}
\hline \multirow{2}{*}{$\begin{array}{l}\text { Number of } \\
\text { postoperative } \\
\text { appointments }\end{array}$} & \multicolumn{2}{|c|}{ Sex } & \multicolumn{3}{|c|}{ Resident population } & \multicolumn{4}{|c|}{ Distance from home to bariatric center } \\
\hline & Male & Female & $\begin{array}{c}\text { City } \\
>100,000\end{array}$ & $\begin{array}{c}\text { Town } \\
<100,000\end{array}$ & Rural & $<5 \mathrm{~km}$ & $5-20 \mathrm{~km}$ & $20-80 \mathrm{~km}$ & $>80 \mathrm{~km}$ \\
\hline Mean (SD) & $5.3(3.4)$ & $5.7(4.7)$ & $4.9(3.4)$ & $5.7(3.8)$ & $5.9(4.2)$ & $5.0(2.9)$ & $5.7(3.8)$ & $5.4(3.4)$ & $4.9(3.8)$ \\
\hline Range & $1.0-17.0$ & $1.0-22.0$ & $1.0-14.0$ & $1.0-22.0$ & $1.0-17.0$ & $1.0-12.0$ & $2.0-22.0$ & $1.0-14.0$ & $1.0-17.0$ \\
\hline Median & 4.0 & 4.0 & 4.0 & 5.0 & 4.5 & 4.0 & 4.0 & 5.0 & 4.0 \\
\hline $95 \% \mathrm{Cl}$ & $4.7-5.9$ & $4.1-7.2$ & $4.1-5.7$ & $4.6-6.7$ & $4.5-7.3$ & $3.3-6.7$ & $3.5-9.5$ & $4.7-6.1$ & $3.4-6.3$ \\
\hline$P$-value & \multicolumn{2}{|c|}{0.875} & \multicolumn{3}{|c|}{0.370} & \multicolumn{4}{|c|}{0.750} \\
\hline
\end{tabular}


lems, including a high rate of band removal because of band-related complications [10]. Kowalewski et al. reported that up to $60 \%$ of patients had band removal within 10 years [11]. In our series, $23 \%$ of patients underwent band removal within 7.5 years after surgery. It needs to be stressed that patients who have their LAGB removed will experience weight regain, independent of current weight, time from index procedure, or cause of removal [12]. Including the patients who underwent band removal and those who did not achieve a successful outcome, the failure rate in the present study was $51 \%$. Poor effectiveness in maintaining long-term weight loss was the most important issue. A meta-analysis published by Nguyen et al. showed that the mean \%EWL in long-term observations (greater than 10 years) ranged from 33\% to $60 \%$ [13]. The 5-year results of the present cohort were published in 2011. At that time, we reported successful outcomes (\%EWL > 50\%) in $24.7 \%$ of patients after 1 year, in $31.5 \%$ after 2 years, and in 38.5\% after 3 years. The increase in the number of patients who achieved \%EWL greater than $50 \%$ was promising and we expected the trend to continue in subsequent years. However, the present analysis showed that only $25 \%$ of patients achieved a successful outcome in long-term observation. Previously reported success rates range from $20 \%$ to $40 \%$ among patients who maintain their bands. Considering that up to $47 \%$ of bands are removed, these rates are low $[2,8,14,15]$. Aarts et al. reported that $67 \%$ of patients achieved a satisfactory \%EWL of over $50 \%$ at some point after LAGB. However, this effect is not permanent; over a 14-year observation period, the percentage decreased to $22 \%[15,16]$. Considering the poor effectiveness of LAGB surgery, we wondered which factors influenced outcomes. We did not identify preoperative BMI as a predictor of weight loss, a result supported by other studies [17-19]. We also did not find any association between age and weight loss. Other authors have reported similar results $[17,18,20]$. Sex was also not associated with weight loss outcomes in the present study. Several papers have suggested that male sex could be negatively associated with weight loss; however, those studies were confounded by low compliance among male patients [7, 20]. Dixon et al. made the interesting observation that male patients who were not compliant were at high risk of weight regain, a finding not present among female patients [21]. Compliance is one of the most important issues in gastric banding surgery. In our study, we found that

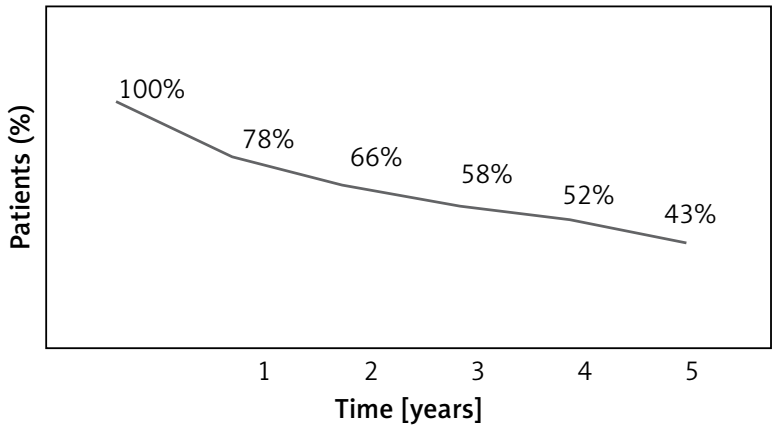

Figure 1. Percentage of patients who attended postoperative appointments

compliance was significantly associated with \%EWL. Patients with successful outcomes more often attended follow-up appointments. This observation is supported by the literature. Sivagnanam et al. found a correlation between the number of postoperative visits and weight loss [22]. Schouten et al. observed a strong association between clinical outcome and the number of postoperative visits [23]. Te Riele et al. reported a higher success rate among compliant patients (40\%) than non-compliant patients (25\%) after gastric band surgery [24]. In a study with a 14-year follow-up, Aarts et al. found that patients who were compliant more often achieved EWL > 50\% than other patients [16]. Although patient compliance is a very important prognostic factor for weight loss, studies have revealed that from $15 \%$ to $45 \%$ of patients do not adhere to postoperative appointments after bariatric surgery $[22,25]$. Our study revealed that $20 \%$ of patients had missed postoperative appointments at 12 months after surgery. At 5 years the percentage of patients who were not compliant had risen to $57 \%$. An analysis of factors influencing compliance showed a positive correlation between age and the number of postoperative appointments. However, older patients did not achieve better weight-loss results than younger patients. We suggested in our previous publication that distance from the hospital and hometown population could be reasons for missing postoperative appointments [5]. However, the present analysis did not find significant associations between these factors and patient compliance. The findings are supported by recent studies $[18,26]$.

Limitations of the present study included the fact that it is a single-center retrospective analysis of a relatively small group of patients. The high percentage of patients who skipped their follow-ups (al- 
though quite typical for the Polish population) might also have influenced the described results.

\section{Conclusions}

This study found that LAGB is not an effective bariatric procedure in long-term observation. Up to $22.8 \%$ of patients required band removal because of various complications within 7.5 years after surgery. Only $25 \%$ of patients who maintained a functioning band achieved \%EWL > 50\%. Sex, age, preoperative $\mathrm{BMI}$, and band volume were not significantly associated with weight loss outcome. Compliance was an independent prognostic factor for weight loss in long-term observation. Older age was the only factor associated with better compliance, while sex, hometown population and distance to the bariatric center were not associated with the number of postoperative appointments.

\section{Conflict of interest}

The authors declare no conflict of interest.

\section{References}

1. Angrisani L, Santonicola A, lovino P, et al. Bariatric surgery worldwide 2013. Obes Surg 2015; 25: 1822-32.

2. Kowalewski PK, Olszewski R, Kwiatkowski A, et al. Life with a gastric band. Long-term outcomes of laparoscopic adjustable gastric banding - a retrospective study. Obes Surg 2017; 27: 1250-3.

3. Walędziak M, Różańska-Walędziak A, Kowalewski P, et al. Present trends in bariatric surgery in Poland. Videosurgery Miniinv 2019; 14: 86-9.

4. Ponce J, Gagner M, O'Brien P. Laparoscopic gastric stapling procedures as a replacement to gastric banding in the $21^{\text {st }}$ century? Bariatr Surg Pract Patient Care 2014; 9: 2-8.

5. Michalik M, Lech P, Bobowicz M, et al. A 5-year experience with laparoscopic adjustable gastric banding - focus on outcomes, complications, and their management. Obes Surg 2011; 21: 1682-6.

6. Brethauer SA, Kim J, el Chaar M, et al. Standardized outcomes reporting in metabolic and bariatric surgery. Surg Obes Relat Dis 2015; 11: 489-506.

7. Busetto L, Segato G, De Marchi F, et al. Outcome predictors in morbidly obese recipients of an adjustable gastric band. Obes Surg 2002; 12: 83-92.

8. Arapis K, Chosidow D, Lehmann M, et al. Long-term results of adjustable gastric banding in a cohort of 186 super-obese patients with a BMI $\geq 50$ kg/m2. J Visc Surg 2012; 149: e143-52.

9. Ponce J, Dixon JB. Laparoscopic adjustable gastric banding. Surg Obes Relat Dis 2005; 1: 310-16.

10. Shen X, Zhang X, Bi J, Yin K. Long-term complications requiring reoperations after laparoscopic adjustable gastric banding: a systematic review. Surg Obes Relat Dis 2015; 11: 956-64.
11. Kowalewski P, Olszewski R, Kwiatkowski A, Paśnik K. Revisional bariatric surgery after failed laparoscopic adjustable gastric banding - a single-center, long-term retrospective study. Videosurgery Miniinv 2017; 12: 32-36.

12. Aarts EO, Dogan K, Koehestanie P, et al. What happens after gastric band removal without additional bariatric surgery? Surg Obes Relat Dis 2014; 10: 1092-96.

13. Ngyuen N, Blackstone R, Morton J, et al. (eds). The ASMBS Textbook of Bariatric Surgery. Vol. 1. Springer-Verlag, New York 2015.

14. Kindel T, Martin E, Hungness E, Nagle A. High failure rate of the laparoscopic-adjustable gastric band as a primary bariatric procedure. Surg Obes Relat Dis 2014; 10: 1070-76.

15. Victorzon M, Tolonen P. Mean fourteen-year, 100\% follow-up of laparoscopic adjustable gastric banding for morbid obesity. Surg Obes Relat Dis 2013; 9: 753-7.

16. Aarts EO, Dogan K, Koehestanie P, et al. Long-term results after laparoscopic adjustable gastric banding: a mean fourteen year follow-up study. Surg Obes Relat Dis 2014; 10: 633-40.

17. Courcoulas AP, Christian NJ, O'Rourke RW, et al. Preoperative factors and 3-year weight change in the Longitudinal Assessment of Bariatric Surgery (LABS) consortium. Surg Obes Relat Dis 2015; 11: 1109-18.

18. Sysko R, Hildebrandt TB, Kaplan S, et al. Predictors and correlates of follow-up visit adherence among adolescents receiving laparoscopic adjustable gastric banding. Surg Obes Relat Dis 2014; 10: 914-20.

19. Benoit SC, Hunter TD, Francis DM, De La Cruz-Munoz N. Use of bariatric outcomes longitudinal database (BOLD) to study variability in patient success after bariatric surgery. Obes Surg 2014; 24: 936-43.

20. Toouli J, Kow L, Ramos AC, et al. International multicenter study of safety and effectiveness of Swedish Adjustable Gastric Band in 1-, 3-, and 5-year follow-up cohorts. Surg Obes Relat Dis 2009; 5: 598-609.

21. Dixon JB, Laurie CP, Anderson ML, et al. Motivation, readiness to change, and weight loss following adjustable gastric band surgery. Obesity 2009; 17: 698-705.

22. Sivagnanam P, Rhodes $M$. The importance of follow-up and distance from centre in weight loss after laparoscopic adjustable gastric banding. Surg Endosc Other Interv Tech 2010; 24: 2432-8.

23. Schouten R, Van't Hof G, Feskens PB. Is there a relation between number of adjustments and results after gastric banding? Surg Obes Relat Dis 2013; 9: 908-12.

24. Te Riele WW, Boerma D, Wiezer MJ, et al. Long-term results of laparoscopic adjustable gastric banding in patients lost to follow-up. Br J Surg 2010; 97: 1535-40.

25. Wheeler E, Prettyman A, Lenhard MJ, Tran K. Adherence to outpatient program postoperative appointments after bariatric surgery. Surg Obes Relat Dis 2008; 4: 515-20.

26. Moroshko I, Brennan L, Warren N, et al. Patient's perspectives on laparoscopic adjustable gastric banding (LAGB) aftercare attendance: qualitative assessment. Obes Surg 2014; 24: 266-75.

Received: 4.01.2019, accepted: 2.03.2019. 